\title{
Are There Learning Agents in Innovative Firms? A Study of the Potential Role of Human Resource Managers in Learning and Innovation
}

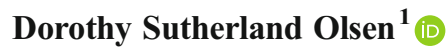

Received: 5 March 2015 / Accepted: 23 June 2015 /

Published online: 23 July 2015

(C) The Author(s) 2015. This article is published with open access at Springerlink.com

\begin{abstract}
This article takes the link between learning and innovation as its starting point and explores how this relationship might be managed within the innovative firm. In order to gain a better overview of the kinds of activities, which might be involved in managing and promoting the kind of learning, which will result in innovation, some criteria have been developed. These criteria are based on a review of the key theoretical and conceptual studies on organisational learning, particularly where these studies relate organisational learning to innovation and change. Thereafter, a close analysis of empirical studies of the relationship between human resource management (HRM) activities and innovation has been carried out. The conclusion is that HRM is already contributing in various ways to learning within innovative firms, and these activities have been linked increased innovation. However, there was no evidence suggesting that HRM is making a strategic connection between learning and business strategy or if they are facilitating connections between pockets of creativity in the organisation, as we might expect from knowledge activists. A better understanding of how HRM works in practice as well as an overview of their aims and strategies would be necessary in order to understand if their activities are explicitly aimed at improving innovation. This article adds to our understanding of HRM activities relating to innovation and provides a systematic overview of how the various HRM activities are linked to theories of learning in innovative organisations.
\end{abstract}

Keywords Learning $\cdot$ Innovative firm $\cdot \mathrm{HRM} \cdot$ Knowledge activist

Theories of innovation have frequently referred to the importance of learning either as an input to innovation or as part of the innovation process (Schumpeter 1947; Lundvall and Johnson 1994; Grønning and Fostenløkken in this issue). Schumpeter suggests that all

Dorothy Sutherland Olsen

Dorothy.olsen@nifu.no

1 Nordic Institute for Studies of Innovation, Research and Education, PB 5183 Majorstuen, 0302 Oslo, Norway 
learning is simply the recombination of facts already known to others, while Lundvall and Johnson (1994) identified a central process of communication and exchange of information occurring while new products and services were being developed. They called this interactive learning. The idea of interactive learning was used to highlight the importance of dialogue between partners as opposed to a one-way communication of information, particularly in the exchange of complex information in the development of new technologies. Jensen et al. (2007) developed this theme by differentiating between the kind of learning that one might expect to result from research collaborations and the kind of learning that one might expect as the result of shared practice. This differentiation was conceptualised in terms of science, technology, and innovation (STI) and doing, using, and interacting (DUI). The names for these two processes indicating their origins, in that STI is based on purposeful, research-based studies directed towards developing new understanding, while DUI is based on practice and stands for doing, using, and interacting, the latter not necessarily being a planned activity but often as a side effect of ordinary work activities. Much of the literature on innovation builds upon the idea that learning, in some form, is one of the central drivers of the innovation process.

One of the important places where much of this learning occurs is in the innovative firm. These firms often engage in deliberate learning in the form of research and development (R\&D) activities. The link between learning through R\&D and being innovative is well understood (Fagerberg et al. 2005; Pavitt 1984). However, within the field of innovation studies, less effort has been devoted to understanding practice-based learning (DUI) and many of the theories used have been drawn from organisational studies, such as the concept of 'learning organisations' (Argyris and Schön 1978; Levitt and March 1988) where the learning is not confined to R\&D units. Some of the studies of learning in the innovative firm or in organisations have been concerned mainly with learning outcomes, while others have studied learning processes, but few have ventured to say much on how learning might be managed. However, in 2005, we find some studies (de Leede and Looise 2005; Shipton et al. 2005) looking more specifically at the role of human resource management (HRM) in innovation and in the same year, we find that, for the first time, the Oslo Manual (OECD and Eurostat 2005) includes questions on organizational innovation in their surveys. Studies on creativity and innovation suggest new definitions of relevant actors in the innovation process, rather than focusing purely on $\mathrm{R} \& \mathrm{D}$, they define a 'creative class', which includes most management occupations and professionals (Lorenz and Lundvall 2011). HRM is seldom referred to in innovation literature; however, in the context of the firm, human resource management is the part of the organisation or the function, which is normally responsible for competence development, recruitment and learning within the firm. The present article picks up some of the ideas explored by de Leede and Looise (2005) and Shipton et al. (2005) and attempts to discover whether HRM as management professionals are, or might become, active players linking learning to innovation. This is done by reviewing how the role of HRM in learning and innovation has been studied and by analysing findings linking HRM actions in a firm to its innovative capabilities.

This paper is organised in the following way: firstly some of the key studies on the learning in innovative organisations are reviewed. The results of this review are used to develop criteria for assessing whether HRM might have what it takes to play an active role in activities related to innovation. More recent studies of HRM, i.e. post-2005, and their contributions to innovation are then reviewed and discussed. 


\section{Method}

The method chosen is the literature review, defined as 'a written document that presents a logically argued case founded on a comprehensive understanding of the current state of knowledge about a topic of study'. (Machi and McEvoy 2009:4).

When studying the relationship between multiple themes, a systematic review of all publications is not appropriate. In this case, the study consists of two stages: firstly, a search of major literary sources was carried out. Firstly, we reviewed key texts on organisational learning in an attempt to find what they said about HRM. These texts were identified by studying reviews of organisational learning literature such as Levitt and March (1988), Dodgson (1993) and Wang and Ahmed (2003) and recent anthologies on the theme, such as Dierkes et al. (2001) and Easterby-Smith and Lyles (2011). Based on these, reviews and key contributors were identified.

The next phase was concentrated on finding theoretic works and empirical studies of HRM related to innovation. This was done by searching databases containing academic publications within social sciences, including management and economics. The search was designed to pick up publications within innovation management and organisational studies. The terms chosen were the general terms used in the organisational management and innovation literature referring to firms, innovation and HRM or human resource management.

A search was carried out of the following EBSCO databases: Academic Search Premier, Business Source Elite, CINAHL, EconLit, ERIC, Regional Business News and SocINDEX.

The search terms used were: Innovation AND (firm* OR compan*) AND (PERSONNEL management OR 'human resource management') AND learning.

This gave us a list of 19 publications between 2006 and 2015 on HRM. Thereafter, publications have been analysed to ascertain if they are descriptive studies of HRM activities related to learning and innovation or if they attempt to demonstrate a link between learning and innovation. The main theoretical directions are summarised and the empirical findings discussed. This paper does not provide a synthesis of studies on the themes, but instead, it selects and discusses the important ideas and arguments which have emerged in recent years relating to the themes of HRM, learning and innovation in the context of the firm. Therefore, the works discussed here in more detail have been chosen because they provide insight into issues relating to innovation, 'in all its particularity and ordinariness' (Onwuegbuzie et al 2012:7). The way in which these articles have been studied is that the main theme has been identified and the links to theories of innovation have been studied more closely; then, these have been compared and discussed. This method is summarised in the table below (Fig. 1).

\begin{tabular}{|l|l|}
\hline Theme analysis & $\begin{array}{l}\text { Involves a search for relationships among domains, } \\
\text { as well as a search for how these relationships are } \\
\text { linked to the overall cultural context. }\end{array}$ \\
\hline Qualitative comparative analysis & $\begin{array}{l}\text { Systematically analyzing similarities and differences } \\
\text { across sources, typically being used as a theory- } \\
\text { building approach, allowing the reviewer to make } \\
\text { connections among previously built categories, as } \\
\text { well as to test and to develop the categories } \\
\text { further. This analysis is particularly useful for } \\
\text { assessing causality in findings across sources. }\end{array}$ \\
\hline
\end{tabular}

Fig. 1 Overview of analytical method 


\section{Organisational Learning and Learning Organisations}

The concept of the learning organization has multiple origins and the literature on the theme is very diverse. As Wang and Ahmed (2003) point out, 'the influx of literature provides overwhelming but unclear information to both researchers and practitioners' (ibid: 8). The works discussed here are key studies relating organisational learning to innovation.

One of the challenges of organisational learning has been to define the links between individual learning and collective learning, which can produce novelty and change. In order to move beyond theories of cognitive learning based on the individual and to look at how whole organisations can learn and change, Argyris and Schön (1978) developed a theory of organizational learning based on action. They suggested that organisational change was based not only on the activities which the firm participated in but also on how they reacted to this participation. This learning is conceptualised as a two-stage process consisting firstly of a process of learning from mistakes and correcting errors. They suggest that that this kind of learning is imperative for continued operations in the firm, and they call this single-loop learning and find many examples of this in various industries. The second stage (double-loop learning) is a more reflective process, whereby organisations obtain feedback from previous successes and failures and use this knowledge to improve or fine-tune their abilities in order to improve their rate of success. For this second process to be effective, they suggest that the organisation should make long-term changes based on the experiences of single-loop learning. They suggest that the outcomes of single-loop learning are quite predictable, but the results of double-loop learning are unpredictable and are likely to be firm specific. This suggests that it is double-loop learning which should produce value for the innovative firm; however Argyris and Schön found few examples of double-loop learning in their studies.

The concept of the learning organisation became popular among business managers in 1990 when Senge became one of the first to publish on this theme (Senge 1990). He introduced a concept where learning was not separated from everyday practice but occurred in environments characterised by their openness to the unexpected and willingness to deal with the unpredictable. He suggests that it is this openness to the unexpected combined with a curiosity about the unknown which promotes firstly learning and then change. Novelty can arise either in the form of new ideas which are stimulated by the process or in the development of new routines as a result of adapting to change. Senge points out that learning from experience is difficult when the effects of an action are not known until much later. He wanted to help practitioners as well as develop theory and he suggested that instead of seeing learning as an activity which can be planned by management, management should instead concentrate on creating an environment for continuous learning. He implies, however, that it is not only management who is responsible for making learning happen but also the individual, the project leaders and not least, teams engaging in collaborative tasks, where learning is an integral part. Although the concepts of Senge were related more to practice than to developing organisational theory, both practitioners and academics recognised the links between his concepts of learning and innovation. 'His ideas were highly attractive because they provided the potential for renewal and growth' (Easterby-Smith and Lyles 2011:12). 
In 1991, March started an interesting discussion on learning by exploitation or exploration started. He takes economic theories of learning as his starting point; these theories were largely based upon the idea that repeated practice produced measurable improvements in productivity. March identified situations where firms utilised the knowledge that they already had to carry out their activities and continually improve their efficiency. He defined this as exploitative learning. To this, he added the concept of learning by exploration, i.e. carrying out tasks deliberately designed to generate new understanding or new knowledge. Explorative learning was characterised as high risk but having the greatest potential for developing competitive advantage. These explorative activities are particularly relevant for innovation, but exploitative learning also produces innovation of the incremental kind. By including both kinds of learning activity, March emphasises that learning, related to innovation, may occur in different parts of the firm and not be confined to R\&D. The most important task for a manager, according to March, was to balance these two forms of learning within the firm.

In his concept of dynamic capabilities, Teece (2007) develops a framework designed to produce continuous novelty within the firm. This framework is based on three dimensions: sensing, i.e. seeing the opportunity for change, seizing is the resulting action in terms of how the firm is going to exploit the opportunities and lastly reconfiguring which outlines how they adjust existing resources and tasks in order to fulfil their plan. The reconfiguring in Teece's framework includes a conscious effort to align or develop existing skills. In terms of learning, the activities relating to reconfiguring would typically include developing new skills and competence. This is not the only part of the framework which is interesting when looking at the links between learning and innovation; indeed, the whole dynamic nature of these capabilities requires continuous learning but perhaps not the conscious kind of learning. Teece argued that some firms develop the ability to exploit opportunities time and time again. He attributes their success to the fact that they have found some hidden key to success, an achievement that would not have been possible without becoming a learning organisation. Successful firms will 'not only adapt to business ecosystems, but also shape them through innovation' (ibid: 1319). Teece refers frequently to the abilities of individuals and to the important role of R\&D; however, it is management who is expected to create the appropriate conditions for dynamic capabilities to develop and flourish in the innovative firm.

Another way of describing an innovative organisation in literature is as a 'knowledge creating company' as Nonaka and Takeuchi (1995) did. They differentiated between the conscious efforts of firms to continuously make small improvements to existing products and the creative activities involved in developing completely new products. Their focus was very much on these creative processes and how firms can provide the conditions necessary for this creativity to thrive. They suggest creating learning environments within firms, where the usual rules are suspended and brainstorming is encouraged. The learning that they describe is in terms of a knowledge creation process based on a combination of communication between groups of employees with diverse backgrounds and experimentation. They suggest that this is the best way to create new ideas and turn them into business opportunities. In innovation processes, creativity is often assumed to be the generation of new ideas occurring at the beginning of a research project or ideas for a new product. However, in the knowledgecreating companies, creativity is not confined to any initial process but can be observed 
at all stages. In the, now famous, example of developing a bread baking machine, it was the novel idea of sending an engineer to work at a bakery which resulted in the final production of a new working product. The cases studied by Nonaka and Takeuchi imply that less planning and less management involvement are needed for these creative processes to flourish in the knowledge-creating organisation.

Management is not considered central to making learning happen in the innovative firm according to Von Krogh et al. (1997). The key player in the creative firm is the knowledge activist. It is suggested that the knowledge activist should function as the connector between creative groups in the organisation, overcoming the challenges of bad communication within large organisations and the ever-present risk of turf wars. It is suggested that the knowledge activist works across the internal boundaries within an organisation. In this way, the knowledge activist (KA) gathers information on projects and ideas, on future needs and on past successes and failures. It is then the KA's responsibility to start matching up people, projects, ideas and activities. The KA then actively facilitates knowledge sharing and creative workshops, where one of the aims is to share tacit knowledge. As well as connecting the right people in the organisation and stimulating knowledge sharing and knowledge creation, the KA also has to leverage this knowledge to business advantage. This latter function has been termed 'merchants of foresight', who select knowledge creation projects and groups who are working on themes which fit in with company strategy and assist in making new products and services which fit in with the company's knowledge vision. It is suggested that the KA can be a group or an individual and it might be a short-term task or a permanent position. It is not considered a managerial role, but it is not specified where in the organisation these person/persons would typically be. What is clear is that the KA must have free reign and be able to follow promising activities; at the same time, the person must be an excellent communicator and have a good understanding of the business and plans for future development.

Another way of describing learning in innovative firms is as a concept of creative abrasion (Leonard 1998). According to Leonard, the term was coined by a director in Nissan, the Japanese automobile producer, and referred to a learning process originating in conflict. This conflict is not aggressive or confrontational and is instead produced by the meeting of different cognitive approaches. The challenge is then to develop different ways of framing the problem or the task and synthesise different problem resolution approaches to achieve a better end result than what any of the individuals could have achieved alone. Leonard (1998) emphasises the importance of understanding the different ways of working within different disciplines and developing good ways of communicating.

These key works on organisational learning provide us with good descriptions and an understanding of the various learning contexts that one might expect to find in the innovative firm. More importantly, they suggest some learning activities which ought to be practiced by innovative firms. In summarising what organisational learning says about learning and innovation, the following points are central:

1. Creating a learning environment or a culture where learning is promoted, and as March and Argyris and Schön suggest, there should be room for error and there should be some way of giving and receiving feedback on what has worked well and what has not worked so well. Not only do these issues require routines and 
accepted practice in order to work but they also require a culture which is open to a certain amount of experimentation and which tolerates errors. The establishment of groups outside the normal organisational structure, groups which are less restricted by internal rules, is advocated by Nonaka and Takeuchi.

2. Dynamism - Both Teece and Senge highlight the importance of dynamism, examples of which can be the continuous drive towards increasing efficiency or the willingness to adapt quickly. Several of the other authors also hint at a kind of dynamism at the individual level, i.e. that employees need to continually renew their knowledge and change (Nonaka and Takeuchi 1995; Leonard 1998; Von Krogh et al. 1997).

3. Communication - Another important issue in the organisational learning literature is the issue of communication. This seems to be an issue at all levels, in all but the smallest firms. The types of communication identified can be communication between management and the rest of the workforce, between project participants, between those working on R\&D or product development and the rest of the organisation as well as communication between firms and other external actors.

4. The continuous renewal of sector specific and firm-specific knowledge is central to the discussions of March (1991) and is considered important to both explorative and exploitative learning. Teece's theory of dynamic firms also builds upon the idea that these firms are continually learning and updating their knowledge.

The organisational learning literature said little about how learning for innovation should be organised or who should be responsible and little about who was actually learning. Argyris and Schön, March and Teece all assume that management take the initiative and play an important role. Senge gives no indication of who should manage this learning, and since everybody is learning Senge's organisation, we might assume that the individual employee is responsible for his or her own learning. Nonaka and Takeuchi suggest that management should create a learning environment for employees working on product development or R\&D. Von Krogh is the only one with a novel suggestion as to who should actively manage learning in the innovative firm: that is the knowledge activist, in a new role created specifically for this function. Otherwise, none of the other key works on organisational learning suggest that HRM as an organisational unit or as a function should attempt to manage or indeed play any role in learning for innovation. In the next section, a review of studies of HRM will be carried to out to see if researchers of HRM have found any contributions to innovation or if there might be any grounds to suggest that HRM should take a more active role in innovation.

\section{Research on Human Resource Management}

In this part of the article, studies on human resource management and innovation are reviewed. There were surprisingly few publications dealing with the joint themes of HRM, learning and innovation, or HRM and innovation. Some theoretical studies were found which link the role of HR to the motivation of employees and to recruitment of employees with interests and abilities deemed to contribute to innovation. There were also some empirical studies of initiatives where HRM was involved. A selection of the papers which specifically studied links or contributions to innovation is discussed here. 
A review of studies of HRM practices and how they contributed to innovation in the form of corporate entrepreneurship was carried out in 2005 (Hayton 2005). In this review, a number of empirical studies are presented and discussed; they are divided into studies of the relationship between HRM and innovation, HRM and corporate venturing as well as HRM and organisational cultures. He finds that many of the earlier studies are of initiatives designed to motivate individuals to innovative behaviour but that they find little or no correlation between financial rewards and increased innovation. He does, however, find that both functional integration and internal training were good indicators of innovation. The review also reports that HRM can encourage team practices and the creation of an environment which is 'supportive of cooperation, promotes the development of human and social capital, and therefore encourages organizational learning' (ibid: 27) and suggests that informal behaviour, development of trust and development of collective interests can be stimulated by proactive HRM practices. The HRM functions identified in Hayton's review are presented in the figure below (Fig. 2).

The search for a framework to integrate HRM and innovation was launched in 2005 (de Leede and Looise 2005) who found that innovation literature contained frequent references to learning among employees and that some literature on HRM contained references to innovation but that there were no studies linking the two. They reviewed earlier studies and discussed how HRM had developed from an administrative function in the 1980s to a more integrated producer of business value in the modern firm. As well as being responsible for enacting the business strategy through recruitment and staff development, HRM typically carried out the following tasks: the design of positions, including the formal descriptions of job content and job rotation, establishing culture or practices of group work and increasing focus on work quality. Career

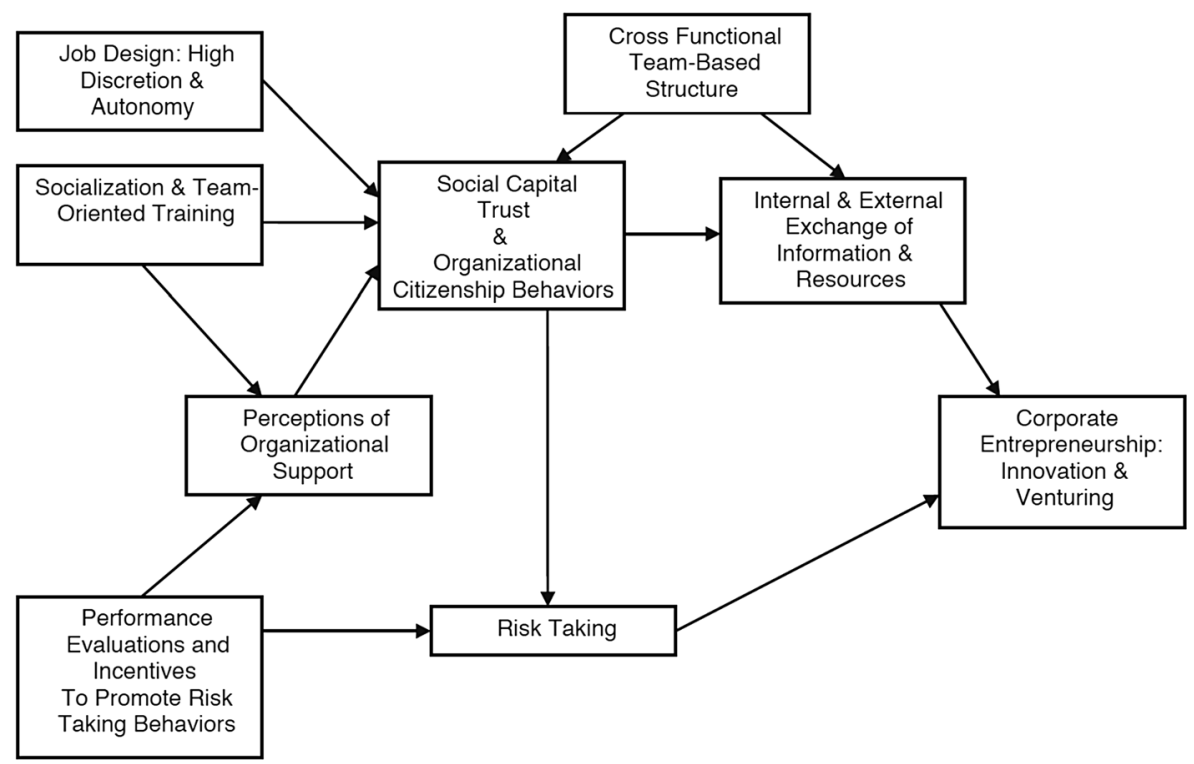

Fig. 2 HRM activities related to innovation and corporate entrepreneurship 
development and training of existing employees was also found to be a central part of their role, as well as assessment of performance and the management of bonuses and profit sharing. de Leede and Looise (2005: 109) also suggest that HRM is the formal channel for communication between management and employees and has the potential to ensure employee participation in the formation of the workplace. In order to indentify the links between HRM and innovation, the authors carried out a case study at Philips CMA, in which they study the development of a new product (the ceramic multilayer actuator), a new organisation and accompanying new practices. For all activities or phases of development, they attempt to identify the role of HRM. They found that HRM involvement changed in accordance with the developmental phase of the new products, with them being most closely involved during the initial phase of recruitment, then later, when they participated directly in coaching and developing new processes of employee influence. The areas where HRM contributed to innovation included the development of a creative culture and searching and selecting people to work within this creative culture. HRM worked constructively to help individuals to develop their careers and was also involved in developing the roles of some of the key individuals (ibid: 112). The authors also concluded that the work of HRM had ensured good communication, participation and effective teamwork.

In the years after this framework was suggested, some interesting studies of organisations and HRM initiatives have been carried out; a selection of these will be reviewed here. The studies reviewed all gathered data via surveys and some included interviews. The first is a study of manufacturing firms in the UK, one of the R\&D-intensive firms in Spain, one of production firms in Italy, one of electronic product manufacturers in Taiwan and one of pharmaceutical firms in Mexico. In all these papers, attempts were made to link HRM practices to innovative activity. All found some correlation. What is interesting for the present study is to look at which theoretical perspectives these studies were based upon and the particular HRM practices that they identified as being relevant to innovation.

In 2005 a study of 111 manufacturing firms was carried out in the UK (Shipton et al 2005). According to the authors, this was the first study of its kind, using empirical data to study the relationships between HRM and innovation. This was a longitudinal study with two rounds of surveys and managerial interviews over an 8-year period. The study aimed to demonstrate that effective HRM practice could 'promote organisational innovation in products and production technologies'. In order to do this, they attempted to assess the sophistication of HRM practices in these 111 firms and secondly to assess and describe their learning climates. HRM sophistication was based upon an assessment of the extensiveness and the quality of the following practices: performance management, recruitment and selection, induction of new employees, training and strategy. Within all these areas, the study had developed criteria for assessing the quality or sophistication of the system. The assessment of the learning climate was based upon the presence of a mentoring system and formal meeting places for interaction between management and employees for the discussion of career development and strategies, policies and vision statements which refer to the importance of employee learning and development. The study found a positive link between innovation and the combined results of HRM sophistication; they also found a significant correlation between a learning climate and innovation. The conclusion is that a combination of individual skills and collective attributes was required in order to innovate successfully. For example, they found that career development increased 
individual competence, but it was invariably followed by a career move, which contributed to the spreading of knowledge and thus increased collective understanding.

The Spanish paper (Cabello-Medina et al. 2011) took, as its starting point, the concepts of intellectual capital and social capital. The HRM processes that they identified as contributing to innovation were as follows:

- Selection processes based on employees' potential to learn

- Selection processes based on interpersonal skills

- Developmental practices such as specific training, career management, mentoring programmes and feedback appraisals

- Developmental practices such as empowerment and employee participation in decision-making

- The use of incentives at the individual and the team level was also investigated but was found to have no influence on innovative activities.

The sample was chosen from firms within an innovative industrial sector (based on number of patents). All firms had over 50 employees and an R\&D department. The questionnaire was sent to the R\&D managers. The study found a correlation between all but the last HRM practices and the firms' innovative activity.

The Italian study (Santangelo and Pini 2011) is interesting in that it attempts to discover not only how HRM practices are implemented but also how they are practiced on the shop floor. The theoretical basis for this study is drawn from studies of entrepreneurship, technological innovation, management and evolutionary economics. The starting point was the idea that HRM practices can improve connections, bridging weak ties and promoting shared mental models. In this study, the emphasis was more on incremental innovation or on exploitative learning rather than explorative learning. Assumptions were made about learning by doing and learning by using, where existing know-how is combined to produce improvements in products and services. Firms within the province of Reggio Emilia (199) responded to the survey; there was prevalence of medium-sized firms (between 100 and 250 employees) and of those working with chemicals or ceramics.

The HRM practices that they identified were as follows:

- Delegation of responsibility

- Quality control responsibility

- Channels for employees to suggest improvements

- Performance incentives

- Flexible labour organisation practices (ranging from routine-based to dynamic)

The study found a positive association between the implementation of new HRM practices on the shop floor and exploitative innovation. They found that productive practice was gradually adapted resulting in productivity improvements, thus suggesting that HRM initiatives contributed to incremental innovation.

The study from Taiwan (Chiang and Shih 2011) was focused on learning in the product development process and sought to demonstrate how 'knowledge-oriented human resource configurations' might support and improve this learning process. This publication takes its point of departure as the knowledge-based theory of the firm (Grant 1996) and is inspired by the concept of dynamic capabilities (Teece et al. 1997). 
They also draw upon Nonaka and Takeuchi's (1995) ideas on cooperative work design. The authors assume that activities which will improve collaboration, learning and accumulation of knowledge can be leveraged in order to improve a firm's innovative performance. The HRM activities that they identify are as follows:

- Cooperative work design

- Recording of work-related experiences

- Appraisal and compensation systems

- Human capital activities such as training and staffing within product development

The survey received responses from 53 vice presidents in charge of HRM and 53 senior managers in the same firms within electrical product development. The survey was supplemented with interviews with 15 mangers responsible for new product development activities. Their study demonstrated a positive relation between knowledge-based HR (i.e. the activities listed above) and the new product development learning process.

Another study carried out on the pharmaceutical industry in Mexico attempted to find out how HRM practices might contribute to innovation. The theoretical basis for this study is March's concept of exploitative and explorative learning and Leonard's concepts of organising internal and external knowledge sources. This study is based on a national data set of all pharmaceutical manufacturers (112). It is not clear exactly how the data was collected or whether the questions were answered by senior management or R\&D. This study differs from the others in that it is sector specific, and as the author points out, the pharmaceutical industry is R\&D intensive and most previous studies of this sector have examined R\&D practices and largely neglected HRM. The author expands on earlier studies by identifying potential links between innovation and the way that employee training is organised, whether recruitment is regulated and employee empowerment. The study found that HRM strategies and the provision of employee training exerted a positive influence on learning processes; more specifically, they found that in firms where employees were encouraged to take external training or training with external instructors, there was more innovation. Links were also identified between innovation and employee empowerment, and they found that the learning most associated with innovation was the more explorative type of learning. It was also found that adopting modern HRM practices including rules governing recruitment influenced innovation.

\section{Discussion}

Although there are not so many studies of HRM relating to innovation, a range of HRM practices which contribute to innovation have been identified. By comparing the different case studies, we can see that different theories are used in designing and analysing survey and interview data. We see that some of the studies view knowledge as a resource and therefore record HRM activities relating to knowledge development, regardless of whether it represents an actual contribution to innovation. Some of the studies are based on ideas of dynamism, risk taking and creative abrasion and thus select only certain HRM activities which they consider relevant to innovation. This has 
resulted in a broad range of activities from a small number of studies. Using the criteria developed from theories of organisational learning, the various HRM activities have been classified as follows (Fig. 3).

The activities contributing to the creation of a learning environment (1) include developing feedback systems and recording of work experiences, two activities which are important prerequisites for learning by doing. The encouragement of teamwork is an activity which would be expected in a knowledge-creating environment as described by Nonaka and Takeuchi and von Krogh. The assertions that HRM develops a creative culture in the organisation are, however, not so useful unless we know exactly what they do. Under item (2) encouraging dynamism, it would appear that HRM is quite active in making an organisation dynamic. The activities identified suggest that HRM is attempting to reduce the risk of employees stagnating in one position in the organisation by managing career development. By opening channels for employee participation in decision-making they are probably reducing the risk of management stagnating in

\begin{tabular}{|c|c|c|}
\hline & Criteria for innovative learning organisation & HRM $_{\text {activities }}{ }^{1}$ \\
\hline 1) & Creating a learning environment & $\begin{array}{l}\text { Developing the appropriate } \\
\text { organisational structure } \\
\text { Creating a creative culture } \\
\text { Fostering effective team working and } \\
\text { team leadership. } \\
\text { Feedback appraisals } \\
\text { Recording of work-related experiences } \\
\text { Selection and recruitment of staff who } \\
\text { have the potential to learn }\end{array}$ \\
\hline 2) & Encouraging dynamism (speed \& change) & $\begin{array}{l}\text { Individual development } \\
\text { Mentoring programmes } \\
\text { Developing roles of key individuals } \\
\text { Management of career development } \\
\text { Selection and recruitment of staff: } \\
\text { - for innovative organisations } \\
\text { - who have the potential to learn } \\
\text { - who have the right interpersonal } \\
\quad \text { skills } \\
\text { Developmental practices such as } \\
\text { empowerment and employee } \\
\text { participation in decision-making. } \\
\text { Including establishing and managing } \\
\text { channels for employees to suggest } \\
\text { improvements. }\end{array}$ \\
\hline 3) & Continually improving communication & $\begin{array}{l}\text { Cooperative work design } \\
\text { Ensuring best possible communication } \\
\text { and participation. }\end{array}$ \\
\hline 4) & $\begin{array}{l}\text { Continuous renewal of sector specific and } \\
\text { firm specific knowledge }\end{array}$ & $\begin{array}{l}\text { Specific training } \\
\text { Human capital activities such as training } \\
\text { and staffing within product development. } \\
\text { Feedback appraisals } \\
\text { Recording of work-related experiences }\end{array}$ \\
\hline
\end{tabular}

Fig. 3 HRM activities contributing to innovation 
their thinking or becoming remote from everyday operations. Avoiding stagnation is considered important in the organisational learning literature; however, we would also expect to find activities designed to improve creativity. Although it is encouraging to see that HRM are active in promoting communications (3) and cooperative work design, there are no activities suggesting that HRM attempts to link creative groups to each other, to pick up ideas and pass them on to those who can act upon them or to link creative activities with firm strategy. It is assumed, yet again, that it is the managers who have to leverage creative endeavour in order to fulfil business strategy. With regard to item 4 , the continuous renewal of sector-specific knowledge, the innovative firms confirm that HRM are indeed ensuring that working knowledge is kept up-todate.

In these studies of HRM, most of the tasks identified as being beneficial for innovation can be placed within the criteria identified in the organisational learning literature. It is evident from the framework developed in 2005 that there is an overlap in the tasks which HRM sees as its responsibility and requirements of an innovative workplace as expressed in these key texts on organisational learning. As de Leede and Looise (2005) point out, the existing literature suggests that researchers of innovation have shown more interest for HRM than researchers of HRM have shown for innovation, and they suggest that innovation researchers look upon HRM as a 'toolkit of specific practices' (ibid: 112). Another interesting point arising from the studies of HRM and innovation is that HRM as a business function has been changing in recent years, and there have been improvements in the way that recruitment and training of employees are linked to business strategy and to performance.

By classifying HRM activities in this way, we achieve two things. Firstly, we gain a more systematic understanding of how the various activities contributed not only to increased innovation, as the studies measured, but also to how these contributions were in fact related to learning activities. Secondly, we are able to assess the suitability of HRM as participants in innovative activity. One of the weaknesses of using these case studies is that few of them tell us what the human resource strategy for the firm was. Information on HR strategy would have made it possible for us to assess whether the HRM activities are part of a planned strategy or if they are perhaps ad hoc solutions to short-term needs.

Thus, the studies reviewed here indicate that HRM are indeed carrying out many of the tasks which are considered important in the innovative organisation. We therefore know that some HR departments are capable of carrying out these tasks. In order to understand whether HRM can really take more responsibility for knowledge creation in the innovative firm, we would really need to know if such practices are widespread or if these examples are merely isolated examples of especially proactive HRM. This might be done by including questions based on the themes identified in this paper in future innovation surveys.

As well as a better understanding of the extent of the practices identified here, it is also important to gain a better understanding of how HRM activities relate to business strategy. It is uncertain whether these HR departments described in this paper are working towards an aim of developing in-house competence, increasing innovation or promoting learning organisations. It is uncertain how HR departments view their own role in the innovative organisation. Do they perhaps see themselves as March's managers, taking strategic decisions, organising accordingly and letting things happen? 
Do they perhaps view their role as being the creators of ideal arenas for knowledge creation, perhaps shielding creative groups from day-to-day requirements? It would be interesting to know if HRM see their role as developing in the direction of knowledge activists, deeply involved in project work and able to see the potential of linking various groups together. In order to gain a better understanding of how HRM function might be developing, in the innovative firm, and how it might be better utilised in innovative processes, would require further study.

The most interesting gap between what innovation studies say that they need and what HRM does is the lack of an obvious bridge between innovative practice and firm strategy. In organisational theory, this was addressed in the role of the knowledge activist. Future studies might look more closely at HRM practices to find out how closely they are involved in innovation activities and gain a better understanding of how HRM aims fit with the needs of the innovative organisation.

Acknowledgments This paper acknowledges the support of the Research Council Norway, project number 228258/H20.

Open Access This article is distributed under the terms of the Creative Commons Attribution 4.0 International License (http://creativecommons.org/licenses/by/4.0/), which permits unrestricted use, distribution, and reproduction in any medium, provided you give appropriate credit to the original author(s) and the source, provide a link to the Creative Commons license, and indicate if changes were made.

\section{References}

Argyris, C., \& Schön, D. A. (1978). Organizational Learning: A theory of action perspective. Reading: Addison-Wesley.

Cabello-Medina, C., Lopez-Cabrales, A., \& Valle-Cabera, R. (2011). Leveraging the innovative performance and social capital in Spanish firms. The International Journal of Human Resource Management, 22(4), 807-828.

Chiang, Y., \& Shih, H. (2011). Knowledge-oriented human resource configurations, the new product development learning process and perceived new product performance. The International Journal of Human Resource Management, 22(15), 3202-3221.

de Leede, J., \& Looise, J. K. (2005). Innovation and HRM: towards an Integrated Framework. Creativity and Innovation Management, 14(2), 108-117.

Dierkes, M., Antal, A. B., Child, J., \& Nonaka, I. (2001). Handbook of organizational learning and knowledge. Oxford: Oxford University Press.

Dodgson, M. (1993). Organizational learning: a review of some literatures. Organization Studies, 14(3), 375394.

Easterby-Smith, M., \& Lyles, M. A. (2011). The handbook of organizational learning and knowledge Management. Oxford: Wiley-Blackwell.

Fagerberg, J., Mowery, D. C., \& Nelson, R. R. (2005). The Oxford handbook of innovation. Oxford: Oxford University Press.

Grant, P. M. (1996). Towards a knowledge based theory of the firm. Strategic Management Journal, 17, 109-122.

Hayton, J. C. (2005). Promoting corporate entrepreneurship through human resource management practices: a review of empirical research. Human Resource Management Review, 15, 21-41.

Jensen, M. B., Johnson, B., Lorenz, E., \& Lundvall, B. A. (2007). Forms of knowledge and modes of innovation. Research Policy, 36(5), 680-693.

Leonard, D. (1998). Wellsprings of knowledge. Harvard: Harvard Business School Press.

Levitt, B., \& March, J. G. (1988). Organizational learning. Annual Review of Sociology, 14, 319-340.

Lorenz, E. \& Lundvall, B. A. (2011). Accounting for creativity in the European union: a multi-level analysis of individual competence, labour market structure, and systems of education and training. Cambridge Journal of Economics, 35, 269-294.

Lundvall, B.-Å., \& Johnson, B. (1994). The learning economy. Journal of Industry Studies, 1(2), $23-42$. 
Machi, L. A., \& McEvoy, B. T. (2009). The literature review: six steps to success. Thousand Oaks: Corwin. March, J. G. (1991). Exploration and exploitation in organizational learning. Organization Science, 2(1), 71-86.

Nonaka, I., \& Takeuchi, H. (1995). The knowledge-creating company: how Japanese companies create the dynamics of innovation. Oxford: Oxford University Press.

OECD \& Eurostat. (2005). The measurement of scientific and technological activities: Oslo manual. European Commision.

Onwuegbuzie, A. J., Leech, N. L., \& Collins, K. M. T. (2012). Qualitative analysis techniques for the review of the literature. The Qualitative Report, 17(56), 1-28.

Pavitt, K. (1984). Sectoral patterns of technical change: towards a taxonomy and a theory. Research Policy, 13, 343-373.

Santangelo, G. D., \& Pini, P. (2011). New HRM practices and exploitative innovation: a shopfloor level analysis. Industry and Innovation, 18(6), 611-630.

Schumpeter, J. A. (1947). Capitalism, socialism and democracy (2nd ed.). New York: Harper \& brothers.

Senge, P. M. (1990). The fifth discipline: the art and practice of the learning organization. London: Century Business.

Shipton, H., Fay, D., West, M., Birdi, M., \& Patterson, K. (2005). Managing people to promote innovation. Creativity and Innovation Management, 14(2), 118-128.

Teece, D. J. (2007). Explicating dynamic capabilities: the nature and microfoundations of (sustainable) enterprise performance. Strategic Management Journal, 28(13), 1319-1350.

Teece, D. J., Pisano, G., \& Shuen, A. (1997). Dynamic capabilities and strategic management. Strategic Management Journal, 18(7), 509-533.

Von Krogh, G., Nonaka, I., \& Ichijo, K. (1997). Develop knowledge activists. European Management Journal, 15(5), 475-483.

Wang, C. L., \& Ahmed, P. K. (2003). Organizational learning: a critical review. The Learning Organization, 10(1), 8-17. 